\title{
HOW JOB AND FAMILY DEMANDS IMPACT CHANGE IN PERCEIVED STRESS: A DYADIC STUDY
}

\author{
EWELINA SMOKTUNOWICZ ${ }^{1}$ and ROMAN CIEŚLAK ${ }^{1,2}$ \\ ${ }^{1}$ SWPS University of Social Sciences and Humanities, Warszawa, Poland \\ Department of Psychology \\ ${ }^{2}$ University of Colorado, Colorado Springs, USA \\ Trauma, Health, and Hazards Center
}

\begin{abstract}
Objectives: The aim of this two-wave study has been to test the spillover and crossover of job and family demands on changes in perceived stress at work and in the family. Specifically, we proposed that demands from one domain (work or family) spilled over to another domain through interrrole conflict (work-family/family-work conflict) and context-specific self-efficacy. Additionally, we hypothesized that changes in perceived stress were impacted not only by a person's own demands through interrole conflict but also by the demands of one's significant other, in the process of crossover. Material and Methods: The study was of dyadic design and it was conducted online, among 130 heterosexual couples, at 2 time points separated by 3 months interval. Hypotheses were verified by means of the path analysis. Results: No support was found for the spillover of job and family demands on changes in perceived stress through interrole conflict and self-efficacy, neither for women nor for men. With regard to the crossover, no support was found for the actor effects, i.e., a person's demands did not impact changes in one's own work- and family-related perceived stress but partial support was found for the partner effects, i.e., women's job demands were associated with men's changes in work and family-related stress through women's work-family conflict, and men's family demands were associated with women's change in family-related perceived stress through men's family-work conflict. Conclusions: The study is a longitudinal test of the Spillover-Crossover model and Work-Home Resources model demonstrating that job and family demands are transmitted across domains and across partners in the intimate relationships through the interrole conflict but the nature of this crossover is different for men and women. Int J Occup Med Environ Health 2018;31(2):199-215
\end{abstract}

Key words:

Job demands, Self-efficacy, Family demands, Spillover-crossover, Dyads, Interrole conflict

\section{INTRODUCTION}

Until lately, a vast majority of research on the work-family interface was focused on the individual level experiences only. However, as Kenny et al. stated in their seminal book "many of the phenomena studied by social and behavioral scientists are interpersonal by definition, and as a result, observations do not refer to a single person but rather to multiple persons embedded within a social context" [1]. Subsequently, a new dimension has been added to reflect that people who balance personal and professional lives are mutually affected by behaviors, thoughts and emotions of other people. This has resulted in an inflow of dyadic studies that allow for testing the transmissions of states and experiences not only across various life domains but also across 2 people.

In this dyadic study we build on the Spillover-Crossover model (SCM) [2] and Work-Home Resources model

Funding: the National Science Center grant No. 2012/07/N/HS6/02547. Grant manager: Ewelina Smoktunowicz, Ph.D.

Received: September 21, 2016. Accepted: January 11, 2017.

Corresponding author: E. Smoktunowicz, SWPS University of Social Sciences and Humanities, Department of Psychology, Chodakowska 19/31, 03-815 Warszawa, Poland (e-mail: esmoktunowicz@swps.edu.pl). 
(W-HR) [3] to investigate the transmission of job and family demands across work and family domains (spillover) and across partners in the intimate relationships (crossover). Both models aim at explaining the relationships between 2 major life domains: work and family. According to the SCM, demands spill over from one domain to another through the interrole conflict (in the form of either work-family or family-work conflict) and then - in the domain that the partners share - various states and experiences may cross over to other people. The WorkHome Resources model, on the other hand, proposes that what connects work and family domains are the personal resources, such as self-efficacy, which get gradually depleted by the demands from the environment.

In response, we propose that for both men and women in the intimate relationships (dyads), job and family demands spill over to family and work domains and impact change in their perceived stress by increasing the interrole conflict and, subsequently, depleting self-efficacy to manage that conflict. Moreover, we expect that interrole conflict predicts the change in perceived stress of the person who experiences that conflict (woman/man) as well as change in stress of their significant other (man/woman). We therefore apply a dyadic design to reflect the interpersonal nature of the phenomenon that is work-family interface.

We contribute to the literature by testing both directions of spillover-crossover process, namely from work to family and from family to work whereas most studies so far have focused only on the former direction [2]. Second, we verify the proposition of the Work-Home Resources model [3] that the link between work and family domains lies in the process in which environmental demands deplete personal resources. To the best of our knowledge, so far this model has not been tested in a dyadic context [4]. Finally, although a few studies tested the crossover of interrole conflict, the results were inconsistent with regard to the role of gender. By using distinguishable dyads in our study (i.e., carrying out the analyses concurrently but separately for men and women) we were able to capture gender differences.

\section{Spillover-Crossover model}

Originally, spillover referred to the process of stress contagion where stress at work transferred to family domain whereas family-related stress became perceptible at work [5]. Although initially the focus was on stress, it soon shifted to include the transmission of positive factors such as resources [6]. Nowadays, spillover is defined in a broader way as a process that occurs within one person but across 2 domains [2]. Negative spillover is usually explained in terms of conflict theory: different life domains are associated with their own set of norms that are often incompatible, and succeeding in one of them often requires making sacrifices in another [7]. This draws directly from the notion that people have a finite set of resources at their disposal, and if they use them in one area they will not be able to benefit from them in another $[8,9]$. This kind of spillover usually takes a form of work-family or family-work conflict.

Crossover, on the other hand, is a transmission within the same domain but across individuals. Studies have found evidence for the crossover of stress [5,10], job burnout [11], and positive factors such as work engagement [12] and daily happiness [13]. In her seminal paper, Westman [10] distinguished 3 possible mechanisms behind crossover. The first is an empathic reaction induced when one of the partners in the couple experiences stress. The second mechanism refers to the stressor that is shared by both partners and therefore it is not, in fact, the crossover that occurs but rather the partners have a stress response to the same stimuli. Finally, crossover could be mediated and/or moderated by factors such as coping and communication strategies, social support, and social undermining.

The Spillover-Crossover model (SCM) [2] integrates previous findings on the spillover and the crossover, and proposes the order in which they follow. Its core proposi- 
tion is that experiences from work domain first spill over to family/home domain and only then cross over to the spouse or life partner through the process of social interaction. When these work-related experiences take the form of job demands they spill over to family domain in the form of work-family conflict, and when they are job resources the spillover becomes work-family enrichment. Importantly, crossover takes place only in the domain that partners share because that is where their social interaction happens. In its original form, the SCM proposed only a direction from work to family but authors noted that it was conceivable to expect also the opposite direction, from family to work [2]. In this study we aim to test the spillover-crossover of job and family demands, and thus we concurrently analyze both directions: from work to family and from family to work.

\section{Work and family: comparing the domains}

Inclusion of both directions of spillover-crossover process requires that we focus on those factors of work and family lives that are comparable across the domains to ensure that meaningful conclusions may be drawn. Although both domains present their own unique sets of demands, according to the influential Job Demands-Resources model [14] there are also the demands that are identifiable in most professions. Furthermore, some of them are applicable outside workplace. One of such factors is perceived quantitative workload defined as a perception of having too many tasks to manage successfully [15]. It is a versatile measure of demands that, although predominantly used for measuring stress at work, has been applied in the family context as well $[16,17]$. There is evidence supporting its relationship with a handful of outcomes such as job burnout [18], physical health [19], and work-family/family-work conflict [15]. However, meta-analytical findings show that, at least in the work domain, the largest effects are found for emotional exhaustion and strain [20].
A general concept that reflects strain experienced both at work and in the family is perceived stress, defined by Cohen et al. [21] as a degree to which people appraise that their demands exceed their ability to cope. Applying a measure that is general and yet possible to customize to a given domain is particularly important because most studies focus on domain-specific outcomes such as job burnout, family satisfaction, and parental stress which renders them incomparable [22]. Moreover, in our study we focus not on the level of perceived stress at a given point in time but on the change in work- and family-related stress over time. This approach is particularly useful in the studies with non-experimental design, where it is expected that time and not an experimental procedure contributes to the changes in a variable, however, so far little research has operationalized perceived stress in such a way.

\section{Spillover of the demands \\ through interrole conflict and self-efficacy}

Work-family conflict was defined by Greenhaus and Beutell [23, p. 77] in their seminal article as "a form of interrole conflict in which the role pressures from the work and family domains are mutually incompatible in some respect. That is, participation in the work (family) role is made more difficult by virtue of participation in the family (work) role." Two directions of the interrole conflict are distinguished: work-family conflict (WFC) when work interferes with family life and family-work conflict (FWC) when family interferes with work. Interrole conflict is a classic example of spillover as it represents the transmission of negative experiences - job and family demands from one domain to another with job demands being followed by WFC and family demands by FWC $[15,24]$.

Recently, another take on the work/non-work nexus has been proposed. In their Work-Home Resources model, Brummelhuis and Bakker [3] have suggested that the spillover from one domain to another is triggered by environmental demands/resources which subsequently 
deplete/enhance personal resources and ultimately result in various job and family outcomes. Authors position personal resources as "the linking pins between the work and home domains" [3, p. 549]. The idea of resources depletion comes from the Conservation of Resources theory (COR) in which Hobfoll refers to loss spiral that occurs when initial loss of resources results in subsequent losses [25].

The Work-Home Resources model tailors the premises of the COR to the context of work-family interface and proposes a sequence in which the resource loss occurs. The Work-Home Resources model has recently been verified in a 3-wave study and it has been found that a particular form of interrole conflict (work-self conflict) leads to reduced task performance through the depletion of personal resources, namely self-efficacy [4]. Negative spillover between work and family domains could be thus comprised not only of the mere conflict between the domains but rather through the sequence of losses: job and family demands followed by work-family/family-work conflict and the subsequent depletion of personal resources. In fact, we found support for this expectation in a previous study [26] which was, however, carried out among individuals only and thus did not take into account the dyadic perspective.

A personal resource that has gained considerable attention in multiple fields of psychology is self-efficacy. Rooted in the Social Cognitive Theory, it is defined as "beliefs in one's capabilities to organize and execute the courses of action required to produce given attainments" [27, p. 3]. General self-efficacy reflects the basic belief in one's ability to cope with demands whereas context-specific selfefficacy reflects beliefs that one can successfully perform in a given life domain. According to Bandura, self-efficacy has the highest predictive power when measured with domain-specific tools rather than with general ones [27] and therefore in this context we use self-efficacy that refers to feeling capable of managing often conflicting demands from 2 major life domains: work and family. Defined in this way, self-efficacy depends on the interrole conflict which, in turn, is a result of the fluctuations in the demands in both life domains; in particular, perceived overload may be volatile and change with circumstances. In order to capture the impact of the demands on perceived stress, through interrole conflict and self-efficacy to manage that conflict, it is more suitable to focus on the change in stress over time rather than on a single point in time.

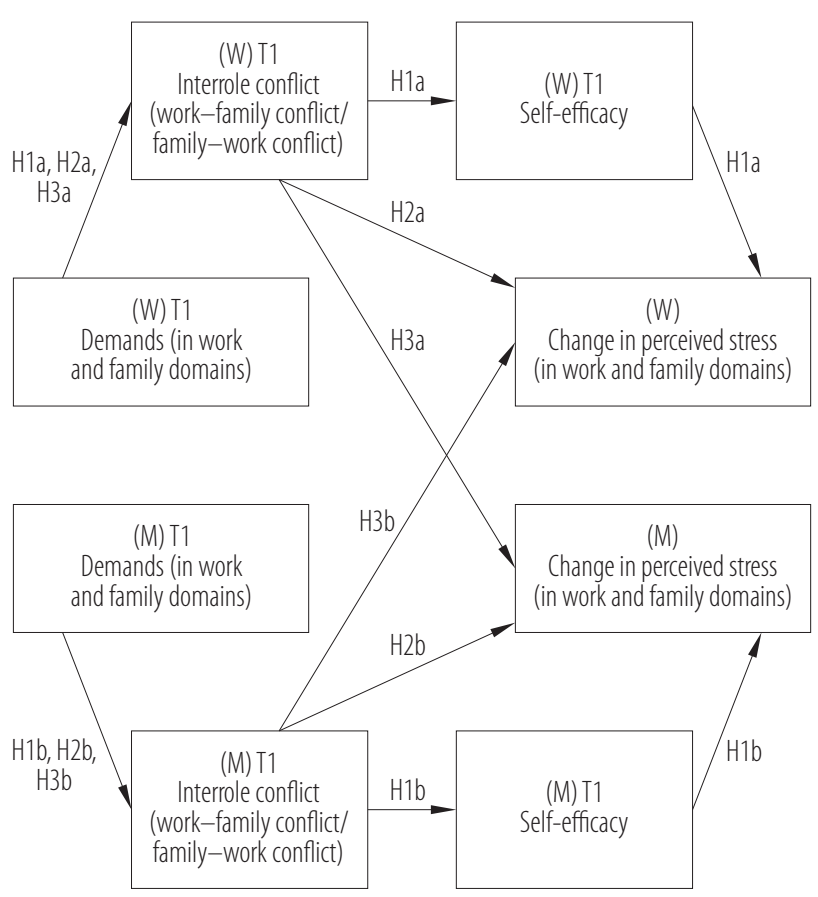

$\mathrm{W}$ - women; M - men.

T1 - measurement at Time 1 (in the study there were 2 measurement points (Time 1 and Time 2) and the interval of 3 months). H1a, H1b - hypotheses 1a and 1b: the impact of women's (men's) T1 job and family demands on the change in their work- and family-related stress is sequentially mediated by their own $\mathrm{T} 1$ interrole conflict (in the form of either work-family or family-work conflict) and T1 self-efficacy to manage that conflict.

$\mathrm{H} 2 \mathrm{a}, \mathrm{H} 2 \mathrm{~b}$ - hypotheses 2a and 2b: the impact of women's (men's) T1 job and family demands on their own change in work- and family-related stress is mediated by their $\mathrm{T} 1$ interrole conflict (actor effects). $\mathrm{H} 3 \mathrm{a}, \mathrm{H} 3 \mathrm{~b}$ - hypotheses 3a and 3b: the impact of women's (men's) T1 job and family demands on men's (women's) change in work- and family-related stress is mediated by women's (men's) T1 interrole conflict (partner effects).

Fig. 1. Hypotheses in the study of job and family demands on changes in perceived stress at work and in the family among heterosexual couples $(\mathrm{N}=130)$ 
We have thus formulated the spillover hypotheses (Figure 1) which we test concurrently for women and men remaining in the intimate relationships:

- Hypothesis 1a: the impact of women's job and family demands on the change in their work- and family-related stress is sequentially mediated by their own interrole conflict (in the form of either work-family or familywork conflict) and self-efficacy to manage that conflict. High demands will be associated with higher interrole conflict which, in turn, will reduce self-efficacy and result in higher change in work- and family-related stress.

- Hypothesis 1b: the impact of men's job and family demands on the change in their work- and family-related stress is sequentially mediated by their own interrole conflict (in the form of either work-family or familywork conflict) and self-efficacy to manage that conflict. High demands will be associated with higher interrole conflict which, in turn, will reduce self-efficacy and result in higher change in work- and family-related stress.

\section{Crossover of the demands through interrole conflict}

As we discussed before, interrole conflict transmits the consequences of demands from one domain to another and it is, in that sense, a spillover. However, not being able to perform in one life area because of the requirements of the other may become a source of stress not only for the person who directly experiences that conflict but also for one's significant others. In other words, after job and family demands increase the interrole conflict, it may subsequently cross over across intimate partners. In dyadic research this crossover is reflected in the approach known as the ActorPartner Interdependence Model (APIM) which refers to a process in which the states and experiences of one person in the dyad may predict their own outcomes (in the so-called actor effects) as well as the outcomes of the other partner in that dyad (in the so-called partner effects) [1].

The idea that interrole conflict may cross over has been already empirically verified and studies have found that outcomes such as distress [28,29], health [30], and relationship tension [31] are predicted not only by individual's own interrole conflict but also that of their partners'. However, a few aspects of the current body of research require addressing. First, studies in which the dyads were distinguishable (i.e., analyses were carried out separately for men and women) delivered inconsistent results on the role of gender in the crossover: some of them indicated differences between men and women [29], and some did not [32]. Second, most of the studies so far were cross-sectional and thus the findings should be corroborated with the data from longitudinal research. Finally, although some studies used both directions of interrole conflict, majority of them implemented only the direction from work to family. In response to these limitations, we test the crossover of both work-family and family-work conflict on the change in perceived stress in work and family domain, separately for women and men. No specific predictions are made on the nature of gender differences because of the mixed findings that have so far been obtained by other researchers. We therefore propose that (Figure 1):

- Hypothesis 2a: the impact of women's job and family demands on their own change in work- and family-related stress is mediated by their interrole conflict (actor effects). High demands will be associated with higher interrole conflict which, in turn, will result in higher change in work- and family-related stress.

- Hypothesis 2b: the impact of men's job and family demands on their own change in work- and family-related stress is mediated by their interrole conflict (actor effects). High demands will be associated with higher interrole conflict which, in turn, will result in higher change in work- and family-related stress.

- Hypothesis 3a: the impact of women's job and family demands on men's change in work- and family-related stress is mediated by women's interrole conflict (partner effects). High demands will be associated with higher interrole conflict which, in turn, will result in higher change in work- and family-related stress. 
- Hypothesis 3b: the impact of men's job and family demands on women's change in work- and family-related stress is mediated by men's interrole conflict (partner effects). High demands will be associated with higher interrole conflict which, in turn, will result in higher change in work- and family-related stress.

\section{MATERIAL AND METHODS}

\section{Procedure}

The study was of longitudinal design with 2 measurement points (Time 1 and Time 2) and the interval of 3 months. Participants in this study were couples and were recruited by undergraduate students working as study assistants as well as a professional research company. In the first case, participants were informed that by filling out the survey at both times they could enter a draw and win prizes, and in the second case the research company had their own incentive plan for participants (they were not paid directly but collected points that could be later exchanged for gifts). Questionnaires were available online and both members of the couple received a link to the survey which they were required to fill out separately.

After 3 months an invitation via e-mail was sent to those couples only who had filled out the survey at Time 1 . Two weeks after the initial invitation, a reminder was sent to everyone who had not yet filled out the survey. The recruitment process resulted in 268 couples completing the questionnaires at Time 1 and 130 couples at Time 2.

\section{Participants}

Participants were heterosexual couples. Both partners needed to have been occupationally active for at least a year and live together for at least as long. The age of participants ranged from 22 to 62 with mean $(\mathrm{M})$ age for women $=34.8($ standard deviation $(\mathrm{SD})=8.76)$ and for men $=35.99(\mathrm{SD}=8.93)$. The couples remained in the relationship for the average of $\mathrm{M}=9.45$ years $(\mathrm{SD}=5.8)$.
Majority of them were married (70\%). Their length of employment ranged from 1 to 43 years with mean length for women $=10.4$ years $(\mathrm{SD}=8.32)$ and for men $=12.94$ years $(\mathrm{SD}=9.08)$. Participants in the sample were well educated with $70 \%$ holding at least a bachelor degree.

\section{Measures \\ Demands at work}

Job demands were measured with the Quantitative Workload Inventory [33]. The scale consists of 5 items and the response scale ranges from 1 ("less than once a month or never") to 5 ("several times a day"). Example items are: "How often does your job require you to work very fast?" and "How often does your job require you to work very hard?". The reliability of the scale for women was $\alpha=0.87$, and for men it was $\alpha=0.83$.

\section{Demands at home}

The Quantitative Workload Inventory was adapted to measure demands at home by replacing the word "work" in the questionnaire with the word "home/family" duties or obligations. Example items are "How often do your home/ family duties require a lot of effort?" and "How often do you have many home/family obligations to do?". Cronbach's $\alpha$ for women was $\alpha=0.86$ and for men $\alpha=0.84$.

\section{Work-family conflict and family-work conflict}

The scale developed by Netemeyer et al. [9] was used for measuring 2 directions of interrole conflict. The scale consists of 5 items for work-family conflict and 5 items for family-work conflict. The response scale ranges from 1 ("strongly disagree") to 7 ("strongly agree"). The scale consists of items such as "The demands of my work interfere with my home and family life" and "I have to put off doing things at work because of demands on my time at home." For WFC scale's reliability for women was $\alpha=0.94$ and for FWC scale it was $\alpha=0.94$. For 
men the reliability of WFC scale was $\alpha=0.94$ and for the FWC $-\alpha=0.95$.

\section{Self-efficacy to manage interrole conflict}

To measure self-efficacy to manage interrole conflict resulting from incompatible demands of work and family roles, a 13-item scale has been created in line with the guidelines provided by Schwarzer and Łuszczyńska [34]. Self-efficacy is usually a unidimensional construct [35] and in this case as well the unidimensional factor structure has been found with $47 \%$ variance explained (eigenvalue $=6.1$ ). Items' factor loadings have ranged between 0.58 and 0.8 . The scale consists of items such as "How capable are you of managing time division between work and family obligations?" and "How capable are you of coping with the family-related stress while being at work?". Cronbach's $\alpha$ was 0.91 for women and 0.94 for men.

\section{Change in work-related stress}

Stress at work was measured with the Perceived Stress Scale (PSS-4) [21] but it was limited to 2 items only. The reliability of the scale increased when the 2 items that were reverse-coded were excluded. The reliability of the scale after this change was for women $\alpha=0.83$ at Time 1 and $\alpha=0.79$ at Time 2 . For men the reliability was $\alpha=0.71$ at Time 1 and $\alpha=0.85$ at Time 2 . The included items were the following: "In the last 3 months, how often have you felt that you were unable to control the important things in your life?" and "In the last 3 months, how often have you felt difficulties were piling up so high that you could not overcome them?".

To measure change in perceived stress, standardized residual values were used as the index of change. They were calculated by entering T2 value of work-related stress as the dependent variable in the regression analysis and $\mathrm{T} 1$ value of this variable as predictor. The residuals are then entered as the outcomes in the analysis [36]. Thus created residuals are calculated before the actual analy- sis and are independent from the baseline (T1) values of the variables. Higher values of the index mean a higher increase of work-related stress and lower values mean a higher decrease of work-related stress.

\section{Change in family-related stress}

The same procedure as described above was applied to the scale measuring stress at home. Here again the scale was reduced to the same 2 items as in the case of work-related scale but the participants were asked to respond in reference to their family situation. The final reliability for women was $\alpha=0.76$ at Time 1 and $\alpha=0.78$ at Time 2 and for men it was $\alpha=0.81$ at Time 1 and $\alpha=0.81$ at Time 2 . The same procedure as in the case of work-related stress was also applied to calculate the change in family-related stress.

\section{Statistics}

Data was analyzed among completers only (i.e., couples that had filled out the questionnaires at both Time 1 and Time 2) by means of the path analysis using IBM SPSS AMOS 22.0 software. Two models were hypothesized to reflect that job demands need to be followed by work-family conflict, and family demands by family-work conflict:

- Model 1 - reflected the following relationship: job demands, work-family conflict, self-efficacy to manage this conflict, change in work- and family-related stress.

- Model 2 - reflected the following relationship: family demands, family-work conflict, self-efficacy to manage this conflict, change in family- and work-related stress.

Both models were estimated using maximum likelihood procedure, and the following indices were used for assessing the model-data fit: root mean square error of approximation (RMSEA) with the cutoff $<0.08$ [37]; comparative fit index (CFI) with the cutoff $>0.90$ [38] and standardized root mean residual (SRMR) with the cutoff $<0.08$ [38]. 
Indirect effects were estimated with the bootstrapping procedure applying bias-corrected $95 \%$ confidence intervals (CI) based on 10000 bootstrap samples [39].

\section{RESULTS}

\section{Preliminary analyses}

\section{Dropout analysis}

Out of 268 couples that at Time 1 filled out the questionnaires, 130 couples $(48.5 \%)$ completed the measurements at Time 2. We performed the Little's Missing Completely at Random (MCAR) test to verify whether data was missing completely at random and found that it did not: $\mathrm{Chi}^{2}=(264)=346.255, \mathrm{p}<0.00$. Participants who dropped out of the study did not differ significantly from those who remained with regard to the how long their relationships lasted $\left(\mathrm{F}(1,255)=0.01, \mathrm{p}=0.93, \eta^{2}=0.00\right)$, length of employment among women, $(\mathrm{F}(1,254)=2.21$, $\left.\mathrm{p}=0.14, \eta^{2}=0.01\right)$, and among men, $(\mathrm{F}(1,263)=3.02$, $\left.\mathrm{p}=0.08, \eta^{2}=0.01\right)$.

However, there were differences regarding the age of participants both among women and men: both women and men who did not fill out the questionnaires at Time 2 were younger than those who did: women $-F(1,266)=5.22, p=0.02, \eta^{2}=0.02$ and men $\mathrm{F}(1,263)=6.05, \mathrm{p}=0.01, \eta^{2}=0.02$. Regarding baseline measures no differences were found -neither among women nor men - regarding job demands, family demands, self-efficacy to manage interrole conflict, and work-related stress.

There were also no differences in terms of work-family conflict among men, but the differences were found for women $\left(\mathrm{F}(1,266)=4.18, \mathrm{p}=0.04, \eta^{2}=0.01\right)$. Those who dropped out of the study declared higher WFC than those who filled out the survey at Time 2. We found no differences among women in terms of family-related stress at Time 1, but we did find them among men $\left(F(1,264)=4.91, p=0.03, \eta^{2}=0.02\right)$. Men who left the study earlier declared lower level of family-related stress at Time 1 . There were also differences - both for women and men - with regard to family-work conflict. Participants who dropped out of the study declared lower level of the FWC, $\mathrm{F}(1,266)=4.78, \mathrm{p}=0.03, \eta^{2}=0.02$ (women) and $F(1,265)=5.24, p=0.02, \eta^{2}=0.02$ (men).

Due to the high dropout rate and the data not missing completely at random the analyses were conducted among completers only $(\mathrm{N}=130)$. However, multiple imputation was applied separately for observations at Time 1 and Time 2 (about $1 \%$ of missing data) to allow for all planned analyses in AMOS.

\section{Correlations}

Means, standard deviations and correlations are displayed in the Table 1 with the bolded values representing correlations between variables of men and women.

\section{Testing the models}

Good model-data fit was found for Model 1 and Model 2 with all 3 indices presenting acceptable values, for Model 1: $\mathrm{CFI}=0.986, \mathrm{SRMR}=0.053$, and RMSEA $=0.026$, and for Model 2: CFI $=0.934$, SRMR $=0.059$, and RMSEA $=0.069$.

\section{Nested models}

Both baseline models were then compared with the set of nested models which were created by constraining to zero the paths representing the hypothesized effects. Each hypothesis comprised one nested model, and additionally we created separate nested models for each outcome (i.e., change in work- and family-related stress). This amounted to 6 nested models for men and 6 nested models for women for both Model 1 and Model 2. If the nested model did not significantly differ from the original model (i.e., $p>0.05$ ) it needed to be accepted as fitting the data better.

If, on the other hand, a given nested model did differ significantly from the baseline model, it needed to 


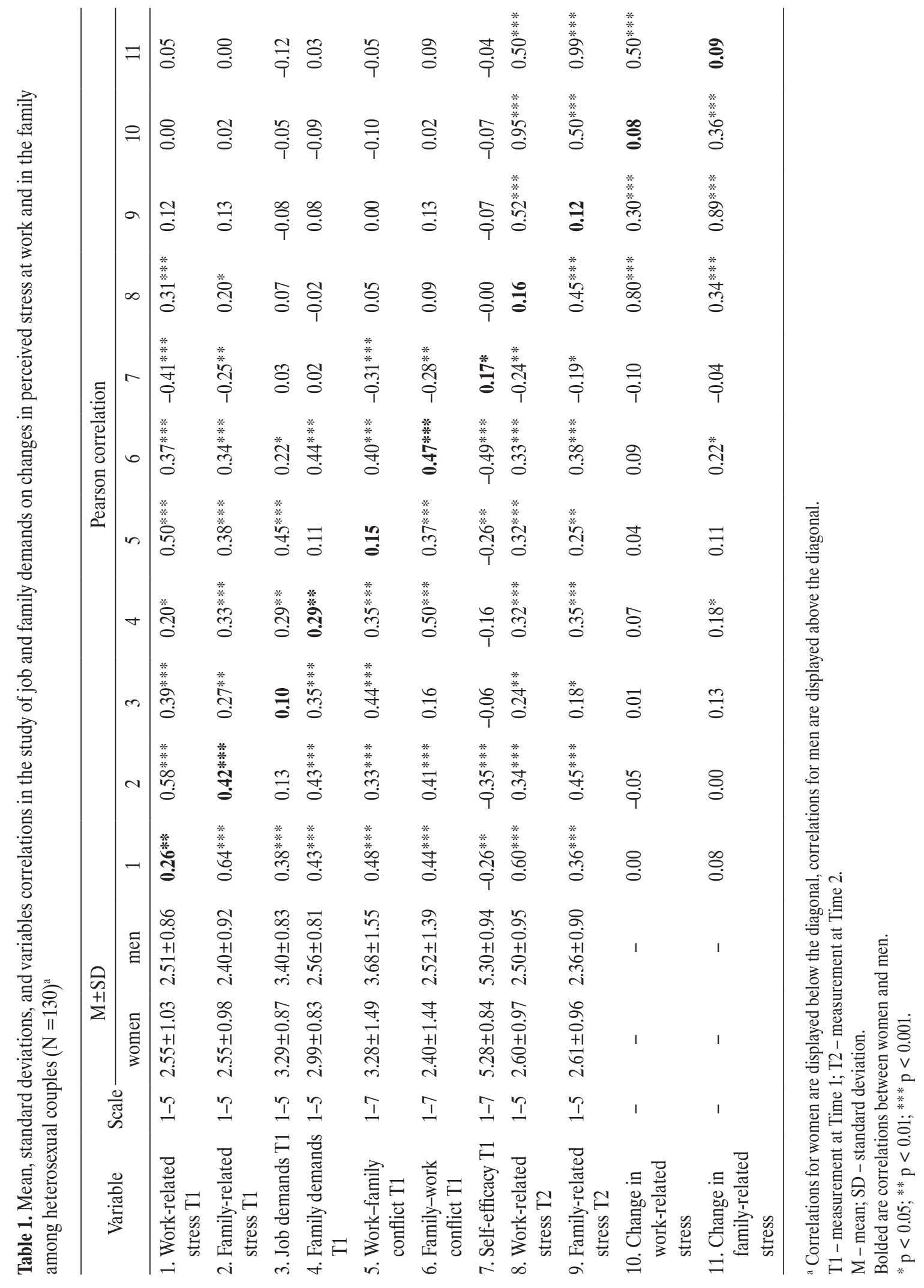


be rejected because the effect which was constrained to zero was important for the model and could not be excluded. Both for baseline Model 1 and for baseline Model 2, all nested models representing study hypotheses differed significantly from the baseline models when the paths were constrained to zero, and needed to be rejected (for Model 1: all p < 0.001; CFI: 0.6730.775, RMSEA: 0.101-0.119; SRMR: 0.077-0.089, and for Model 2: all p < 0.001, CFI: 0.626-0.863; RMSEA: 0.100-0.155; SRMR: 0.088-0.123). Therefore, the baseline models remained unchanged.

\section{Testing the hypotheses}

Hypothesis 1a and 1b have suggested that the impact of a person's job and family demands on one's own change in work- and family-related stress is mediated by first their own interrole conflict, and then self-efficacy to manage that conflict. Hypothesis 1a refers to women and hypothesis $1 \mathrm{~b}$ to men. Women and men's T1 job demands are significantly associated with their higher T1 work-family conflict (for women: standardized regression coefficient $(\beta)=0.454$, standard error $(\mathrm{SE})=0.132$; for men: $\beta=0.453, \mathrm{SE}=0.143$ ), and women and men's T1 family demands are significantly associated with their higher $\mathrm{T} 1$ familywork conflict (for women: $\beta=0.465, \mathrm{SE}=0.124$; for men: $\beta=0.365$, SE $=0.129$ ). In turn, T1 WFC is related to lower T1 self-efficacy to manage that conflict (for women: $\beta=-0.224$, $\mathrm{SE}=0.046$; for men: $\beta=-0.333$, $\mathrm{SE}=0.049$ ), as T1 FWC is (for women: $\beta=-0.461$; $\mathrm{SE}=0.045$; for men: $\beta=-0.270$; $\mathrm{SE}=0.058$ ). However, there has been no relationship between T1 selfefficacy and change in women and men's perceived stress, neither at work nor at home. Therefore hypotheses $1 \mathrm{a}$ and $1 \mathrm{~b}$ have not been supported (Table 2-5). Hypothesis $2 \mathrm{a}$ and $2 \mathrm{~b}$ referr to the actor effects in the crossover of interrole conflict and we have expected that change in work- and family-related stress of a person would be predicted by their own job and family demands through the increase in their own interrole conflict. Hypothesis 2a refers to women and hypothesis $2 b$ refers to men. Again, we have found that $\mathrm{T} 1$ work-family conflict is predicted by women and men's T1 job demands, and T1 family-work conflict is predicted by women and men's T1 family demands, however, we have found no relationship between either form of T1 interrole conflict and change in workand family-related stress, neither for women nor men. Thus, hypothesis $2 \mathrm{a}$ and hypothesis $2 \mathrm{~b}$ have not been supported, either (Table 2-5).

Hypothesis $3 \mathrm{a}$ and $3 \mathrm{~b}$ refer to the partner effects in the crossover of interrole conflict and have suggested that change in a person's work- and family-related stress would be predicted by the job and family demands of their partner through the increase in their partner's interrole conflict. Hypothesis 3 a refers to the impact of women's demands on men's change in perceived stress and hypothesis $3 b$ refers to the impact of men's demands on women's change in perceived stress.

We have found that women's T1 job demands are associated with change in men's work-related stress via the increase in women's T1 work-family conflict $(\beta=0.089$, $\mathrm{SE}=0.043,95 \% \mathrm{CI}: 0.011-0.180)$, as well as with change in men's family-related stress $(\beta=0.074, \mathrm{SE}=0.040$, 95\% CI: 0.002-0.159). As for women's T1 family demands, we have found no significant relationships with neither men's change in work- nor family-related stress. Therefore, hypothesis 3 a has been partially supported. Similarly, we have found no associations between men's T1 job demands and women's change in stress. However, men's family demands at Time 1 have had an indirect effect on women's change in familyrelated stress via the increase in men's T1 family-work conflict ( $\beta=0.096, \mathrm{SE}=0.044,95 \% \mathrm{CI}$ : 0.028-0.206). Hypothesis $3 \mathrm{~b}$ has also been partially supported (Table 2-5). 
Table 2. Mediation analyses for Model $1 *$ in the study of job demands on changes in perceived stress at work and in the family among heterosexual couples $(\mathrm{N}=130)$ - outcomes for women

\begin{tabular}{lcccccccc}
\hline & \multicolumn{1}{c}{ Outcome } \\
\cline { 2 - 9 } \multicolumn{1}{c}{ Variable } & $\begin{array}{c}\text { T1 work-family conflict } \\
\text { (mediator 1) }\end{array}$ & $\begin{array}{c}\text { T1 self-efficacy } \\
\text { (mediator 2) }\end{array}$ & \multicolumn{2}{c}{$\begin{array}{c}\text { change } \\
\text { in work-related stress }\end{array}$} & $\begin{array}{c}\text { change } \\
\text { in family-related stress }\end{array}$ \\
\cline { 2 - 10 } & $\beta$ & SE & $\beta$ & SE & $\beta$ & SE & $\beta$ & SE \\
\hline T1 Job demands (W) & 0.454 & 0.132 & & & & & & \\
T1 Work-family conflict (W) & & & -0.224 & 0.046 & 0.003 & 0.048 & 0.103 & 0.052 \\
T1 Self-efficacy (W) & & & & & -0.122 & 0.085 & -0.007 & 0.093 \\
T1 Work-family conflict (M) & & & & & 0.048 & 0.045 & 0.055 & 0.049 \\
\hline
\end{tabular}

* Model 1 - reflected the following relationship: job demands, work-family conflict, self-efficacy to manage this conflict, change in workand family-related stress.

T1 - measurement at Time 1 (in the study there were 2 measurement points (Time 1 and Time 2) and the interval of 3 months).

$\mathrm{W}$ - women; $\mathrm{M}$ - men.

$\beta$ - standardized regression coefficient; SE - standard error.

Table 3. Mediation analyses for Model $1^{*}$ in the study of job demands on changes in perceived stress at work and in the family among heterosexual couples $(\mathrm{N}=130)$ - outcomes for men

\begin{tabular}{lcccccccc}
\hline & \multicolumn{9}{c}{ Outcome } \\
\cline { 2 - 8 } \multicolumn{1}{c}{ Variable } & $\begin{array}{c}\text { T1 work-family conflict } \\
\text { (mediator 1) }\end{array}$ & $\begin{array}{c}\text { T1 self-efficacy } \\
\text { (mediator 2) }\end{array}$ & \multicolumn{2}{c}{$\begin{array}{c}\text { change } \\
\text { in work-related stress }\end{array}$} & $\begin{array}{c}\text { change } \\
\text { in family-related stress }\end{array}$ \\
\cline { 2 - 9 } & $\beta$ & SE & $\beta$ & SE & $\beta$ & SE & $\beta$ & SE \\
\hline T1 Job demands (M) & 0.453 & 0.143 & & & & & & \\
T1 Work-family conflict (M) & & & -0.333 & 0.049 & -0.150 & 0.057 & -0.085 & 0.054 \\
T1 Self-efficacy (M) & & & & & -0.051 & 0.088 & -0.047 & 0.089 \\
T1 Work-family conflict (W) & & & & & 0.197 & 0.053 & 0.163 & 0.053 \\
\hline
\end{tabular}

Explanations as in Table 2.

Table 4. Mediation analyses for Model $2 *$ in the study of family demands on changes in perceived stress at work and in the family among heterosexual couples $(\mathrm{N}=130)$ - outcomes for women

\begin{tabular}{|c|c|c|c|c|c|c|c|c|}
\hline \multirow{3}{*}{ Variable } & \multicolumn{8}{|c|}{ Outcome } \\
\hline & \multicolumn{2}{|c|}{$\begin{array}{l}\mathrm{T} 1 \text { family-work conflict } \\
\text { (mediator 1) }\end{array}$} & \multicolumn{2}{|c|}{$\begin{array}{l}\text { T1 self-efficacy } \\
\text { (mediator 2) }\end{array}$} & \multicolumn{2}{|c|}{$\begin{array}{c}\text { change } \\
\text { in work-related stress }\end{array}$} & \multicolumn{2}{|c|}{$\begin{array}{c}\text { change } \\
\text { in family-related stress }\end{array}$} \\
\hline & $\beta$ & SE & $\beta$ & SE & $\beta$ & SE & $\beta$ & SE \\
\hline T1 Family demands (W) & 0.465 & 0.124 & & & & & & \\
\hline T1 Family-work conflict (W) & & & -0.461 & 0.045 & 0.078 & 0.057 & 0.124 & 0.059 \\
\hline T1 Self-efficacy (W) & & & & & -0.088 & 0.094 & 0.074 & 0.097 \\
\hline T1 Family-work conflict (M) & & & & & -0.069 & 0.054 & 0.263 & 0.056 \\
\hline
\end{tabular}

* Model 2 - reflected the following relationship: family demands, family-work conflict, self-efficacy to manage this conflict, change in workand family-related stress.

Other explanations as in Table 1. 
Table 5. Mediation analyses for Model 2* in the study of family demands on changes in perceived stress at work and in the family among heterosexual couples $(\mathrm{N}=130)$ - outcomes for men

\begin{tabular}{|c|c|c|c|c|c|c|c|c|}
\hline \multirow{3}{*}{ Variable } & \multicolumn{8}{|c|}{ Outcome } \\
\hline & \multicolumn{2}{|c|}{$\begin{array}{l}\text { T1 family-work conflict } \\
\text { (mediator 1) }\end{array}$} & \multicolumn{2}{|c|}{$\begin{array}{l}\text { T1 self-efficacy } \\
\text { (mediator 2) }\end{array}$} & \multicolumn{2}{|c|}{$\begin{array}{c}\text { change } \\
\text { in work-related stress }\end{array}$} & \multicolumn{2}{|c|}{$\begin{array}{c}\text { change } \\
\text { in family-related stress }\end{array}$} \\
\hline & $\beta$ & SE & $\beta$ & SE & $\beta$ & SE & $\beta$ & SE \\
\hline T1 Family demands (M) & 0.365 & 0.129 & & & & & & \\
\hline T1 Family-work conflict (M) & & & -0.270 & 0.058 & 0.006 & 0.065 & 0.077 & 0.064 \\
\hline T1 Self-efficacy (M) & & & & & -0.027 & 0.089 & -0.032 & 0.089 \\
\hline T1 Family-work conflict (W) & & & & & 0.012 & 0.060 & -0.005 & 0.059 \\
\hline
\end{tabular}

Explanations as in Table 1 and 4.

\section{DISCUSSION}

The aim of this study has been to test spillover and crossover of the demands across work and family domains and across partners remaining in intimate relationships. We have proposed that job and family demands would spill over to family and work domains through work-family or family-work conflict respectively, and then decrease self-efficacy to manage that conflict, ultimately leading to changes in work- and family-related perceived stress. Moreover, we have expected that the demands could predict change in perceived stress for the person experiencing those demands as well as the change in stress of their significant others through the crossover of interrole conflict. We have found no support for our first expectation. Although for both men and women, their job and family demands are associated with higher interrole conflict, which in turn has depleted their self-efficacy to manage this conflict, the self-efficacy itself has had no impact on changes in perceived stress for neither of the partner. The Work-Home Resources model proposes that environmental demands lead to the depletion of personal resources which are said to be the link between work and family domains [3], and our findings support this notion to the extent that the demands do diminish personal resources through an increase in interrole conflict. Perhaps the subsequent lack of relationship between self-efficacy and the outcomes is caused by the way perceived stress has been measured in this study. The interval between its measurements is only 3 months and although it is sufficient to reflect short-term effects [40], it might not be enough to capture the change in stress resulting from decreased self-efficacy.

Although self-efficacy is a modifiable variable [27] its strengthening or depletion might require longer time. Additionally, it is possible that it is the change over time and not the level of self-efficacy that constitutes the mechanism. Predictive - however not mediating - role of change in coping self-efficacy was previously found in the study focused on posttraumatic stress [41] and future research could investigate its applicability in the context of stress related to work-family interface.

Moreover, we have included a context-specific self-efficacy, the one that heavily depends on the participants' interrole conflict. This dependence has been confirmed by high regression weights of self-efficacy on work-family and family-work conflict among both men and women. Interrole conflict in turn is a direct result of the demands imposed on the person (again, these relationships have been confirmed in our analyses) which may be very volatile and vary depending on the current situation in people's personal and professional lives. This could also explain why no support has been found for the second hypothesis. 
We have expected that a person's change in perceived stress would be predicted by their own demands through interrole conflict and that capturing the impact of demands on perceived stress would require defining the outcome in terms of change rather than a point in time. However, here again 3 months might not have been a sufficiently long time for the changes in perceived stress to develop. Future studies should apply longer time intervals as well as control for the current situation at work and in the family.

We have found partial support for our third set of expectations with regard to the crossover of interrole conflict across intimate partners (so-called partner effects). Specifically, women's job demands have been associated with higher change in men's perceived stress both at work and at home through the elevation in women's work-family conflict. On the other hand, men's family demands have resulted in higher change in women's perceived stress at home but not at work - via the increase in men's family-work conflict. However, there is no impact of women's family demands on change in men's perceived stress or of men's job demands on change in women's perceived stress. These results are indicative of gender differences when it comes to crossover of interrole conflict and are in line with some of the previous empirical findings.

For example, Shimazu et al. [29] in their study on a Japanese sample found that women's distress was caused by men's FWC but men's distress was unaffected by women's FWC. However, there is also a body of research which shows no gender differences in the crossover of interrole conflict [32]. Results from this study seem to reflect situations in which roles are assigned along the gender lines. Since the WFC indicates that a person underperforms at home due to the obligations at work, when women feel they cannot fully meet the expectations of their role as a wife/life partner or a parent, this becomes a source of stress for men.

This stress is experienced by men at home which is straightforward enough as partners share this domain and the results of women's WFC are more tangible there. Men's change in perceived stress at work might in itself be a form of spillover: discomfort related to the situation at home lingers even when the context is changed from family to work. Men's change in stress remain unaffected by women's FWC, i.e., women's inability to perform well at work. Men could feel that this is not a threat to them and, therefore, does not contribute to their stress development.

The situation is different in the case of women's change in perceived stress. It is only affected in the family domain and only by men's family demands via their FWC. We speculate that women become more stressed over time when they feel that their partners do not meet expectations imposed on them at work due to the obligations they have at home. This could be attributed either to women's sense of guilt or to the financial aspect because men often remain primary breadwinners. Women might not be bothered with men's WFC, again for the traditional reasons, meaning that men's contribution to the family life is often considered optional and therefore, them not being able to meet the demands of family life is not stress-inducing.

Taken together, we have found only partial support for the Spillover-Crossover model [2] and the Work-Home Resources model [3]. We have shown indeed that both job and family demands spill over to domains of family and work respectively through the interrole conflict and that this conflict depletes context-specific personal resources. We have been unable, however, to demonstrate that this spillover impacts general strain in the form of perceived stress. In terms of crossover, we have found evidence for the role of gender in the process of crossover of demands through work-family and family-work conflicts.

In practical terms, results of the study show that the consequences of demands go beyond the person who experiences them, and also beyond the domain they originate from. We have demonstrated that demands are associated with decreased self-efficacy and, in some cases, changes 
in perceived stress, and that this process is mediated by interrole conflict.

One way of managing the interrole conflict is through the implementation of flexible work arrangements (FWAs) at the organizations. They include possibility to work remotely (i.e., from locations other than the office), reduced hours, child centers at work and many others [42]. However, currently the effectiveness of FWAs is still limited. Benefits from FWAs are possible only when employees feel that they can use them without being worried about repercussions from the supervisors and co-workers [43]. Second, FWAs are often adopted only for chosen groups of employees and only among specific groups of industries that look to attract and retain workers with highly specialized skills [43]. Third, usually only the basic FWAs are implemented such as telework or flexible time schedule while there is a variety of options to be considered $[42,44]$.

One of those options is reducing the workload which is often perceived as unfeasible by the organizations, despite the fact, that the demands are the very factors that lead to interrole conflict and further losses. We have also shown how changes in stress are impacted by the partner's demands through their interrole conflict and we have highlighted how they could be indicative of the traditional division of labor in the families. The crossover of demands through interrole conflict shows that reducing that conflict is in the best interest not only of the individual but also that of their partner's.

This study has a few limitations. It consists of 2 waves while ideally there should be 4 to fully capture the spillover-crossover over time. One of the reasons for not including more measurement points has been the already high dropout rate $(51.5 \%)$ between Time 1 and Time 2. This, in turn, could be attributed at least partially to the length of the study which took the participants approximately 25-30 min to fill out, as it was a part of a larger project. Moreover, we did not include any demographic variables because the models were already complex for the sample of 130 dyads. However, including the length of relationship and family situation (e.g., number and age of children) could further contribute to the understanding of the relationship between intimate partners in work and family domains. Finally, the interval between the measurements could be longer to allow for changes in work and family situations of the participants to develop.

\section{CONCLUSIONS}

To summarize, with this longitudinal study we have contributed to the literature by testing the Spillover-Crossover model [2] in both directions: from work to family, and from family to work. Obtained results have partially confirmed our expectations. We have shown that job demands as well as family ones spill over to other life domains through interrole conflict and deplete one's beliefs about being able to manage this conflict. In some cases, interrole conflict of one partner predicts changes in stress of the other partner but the pattern of this crossover is different depending on the gender. With the results of these studies we also open avenues for future research.

The lack of significant relationships between self-efficacy and changes in perceived stress leaves open a question about the development of stress reaction in response to the loss of personal resources in a dyadic context. It also raises another possibility, namely that self-efficacy operates as a moderator rather than a mediator. In our study we have not focused on this approach because the role of self-efficacy needs to stem from the assumed theoretical approach. In this case it is the Work-Home Resources model which directly refers to the personal resources as the mediating factor in the relationship between the demands and the outcomes.

However, future studies could focus on when or for whom demands predict perceived work- and family-related stress depending on the levels of self-efficacy. Additionally, it would be interesting to investigate whether the crossover of job and family demands through the interrole conflict would be different among non-traditional couples, e.g., those in which women are the primary breadwinners. 


\section{REFERENCES}

1. Kenny DA, Kashy DA, Cook WL. Dyadic data analysis. New York: Guilford Press; 2006.

2. Bakker AB, Demerouti E. The spillover-crossover model. In: Grzywacz JG, Demerouti E, editors. New frontiers in work and family research. New York: Psychology Press; 2013. p. 55-70.

3. Brummelhuis LL, Bakker AB. A resource perspective on the work-home interface: The work-home resources model. Am Psychol. 2012;67(7):545-56, https://doi.org/10.1037/ a0027974.

4. Demerouti E, Sanz-Vergel AI, Petrou P, van den Heuvel M. How work-self conflict/facilitation influences exhaustion and task performance: A three-wave study on the role of personal resources. J Occup Health Psychol. 2016;21(4): 391-402, https://doi.org/10.1037/ocp0000022.

5. Bolger N, Delongis A, Kessler RC, Wethington E. The contagion of stress across multiple roles. J Marriage Fam. 1989;51(1):175-83, https://doi.org/10.2307/352378.

6. Grzywacz JG, Marks NF. Reconceptualizing the work-family interface: An ecological perspective on the correlates of positive and negative spillover between work and family. J Occup Health Psychol. 2000;5(1):111-26, https:/doi. org/10.1037/1076-8998.5.1.111.

7. Zedeck S, Mosier KL. Work in the family and employing organization. Am Psychol. 1990;45(2):240-51, https:/doi. org/10.1037/0003-066X.45.2.240.

8. Carlson DS, Kacmar KM, Williams LJ. Construction and initial validation of a multidimensional measure of work-family conflict. J Vocat Behav. 2000;56(2):249-76, https://doi. org/10.1006/jvbe.1999.1713.

9. Netemeyer RG, Boles JS, McMurrian R. Development and validation of work-family conflict and family-work conflict scales. J Appl Psychol. 1996;81(4):400-10, https://doi. org/10.1037/0021-9010.81.4.400.

10. Westman M. Stress and strain crossover. Hum Relat. 2001; 54(6):717-51, https://doi.org/10.1177/0018726701546002.

11. Bakker AB, Demerouti E, Schaufeli WB. The crossover of burnout and work engagement among working couples. Hum Relat. 2005;58(5):661-89, https://doi.org/10. 1177/0018726705055967.

12. Bakker AB, Xanthopoulou D. The crossover of daily work engagement: Test of an actor-partner interdependence model. J Appl Psychol. 2009;94(6):1562-71, https://doi.org/ 10.1037/a0017525.

13. Rodríguez-Muñoz A, Sanz-Vergel A, Demerouti E, Bakker A. Engaged at work and happy at home: A SpilloverCrossover model. J Happiness Stud. 2014;15(2):271-83, https://doi.org/10.1007/s10902-013-9421-3.

14. Demerouti E, Nachreiner F, Baker AB, Schaufeli WB. The job demands-resources model of burnout. J Appl Psychol. 2001;86(3):499-512, https://doi.org/10.1037/00219010.86.3.499.

15. Michel JS, Kotrba LM, Mitchelson JK, Clark MA, Baltes BB. Antecedents of work-family conflict: A meta-analytic review. J Organ Behav. 2011;32(5):689-725, https://doi. org/10.1002/job.695.

16. Frone MR, Yardley JK, Markel KS. Developing and testing an integrative model of the work-family interface. J Vocat Behav. 1997;50(2):145-67, https://doi.org/10.1006/ jvbe.1996.1577.

17. Van Rijswijk K, Bekker MHJ, Rutte CG, Croon MA. The relationships among part-time work, work-family interference, and well-being. J Occup Health Psychol. 2004;9(4): 286-95, https://doi.org/10.1037/1076-8998.9.4.286.

18. Hakanen JJ, Schaufeli WB, Ahola K. The Job Demands-Resources model: A three-year cross-lagged study of burnout, depression, commitment, and work engagement. Work Stress. 2008;22(3):224-41, https://doi.org/ 10.1080/02678370802379432.

19. Nixon AE, Mazzola JJ, Bauer J, Krueger JR, Spector PE. Can work make you sick? A meta-analysis of the relationships between job stressors and physical symptoms. Work Stress. 2011;25(1):1-22, https://doi.org/10.1080/02678373.20 11.569175 .

20. Bowling NA, Alarcon GM, Bragg CB, Hartman MJ. A meta-analytic examination of the potential correlates 
and consequences of workload. Work Stress. 2015;29(2): 95-113, https://doi.org/10.1080/02678373.2015.1033037.

21. Cohen S, Kamarck T, Mermelstein R. A global measure of perceived stress. J Health Soc Behav. 1983;24(4):385-96, https://doi.org/10.2307/2136404.

22. Peeters MCW, Brummelhuis LL, van Steenbergen EF. Consequences of combining work and family roles: A closer look at cross-domain versus within-domain relations. In: Grzywacz JG, Demerouti E, editors. New frontiers in work and family research. New York: Psychology Press; 2013. p. 93-109.

23. Greenhaus JH, Beutell NJ. Sources of conflict between work and family roles. Acad Manage Rev. 1985;10(1):76-88, https://doi.org/10.5465/AMR.1985.4277352.

24. Byron K. A meta-analytic review of work-family conflict and its antecedents. J Vocat Behav. 2005;67(2):169-98, https://doi.org/10.1016/j.jvb.2004.08.009.

25. Hobfoll SE. Social and psychological resources and adaptation. Rev Gen Psychol. 2002;6(4):307-24, https://doi.org/ 10.1037/1089-2680.6.4.307.

26. Smoktunowicz E, Cieślak R, Demerouti E. Interrole conflict and self-efficacy to manage work and family demands mediate the relationships of job and family demands with stress in the job and family domains. Anxiety Stress Coping. 2017;30(5):485-97, https://doi.org/10.1080/10615806.2017. 1329932.

27. Bandura A. Self-efficacy: The exercise of control. New York: Henry Holt \& Co; 1997.

28. Cowlishaw S, Evans L, McLennan J. Work-family conflict and crossover in volunteer emergency service workers. Work Stress. 2010;24(4):342-58, https://doi.org/10.1080/02678373. 2010.532947.

29. Shimazu A, Kubota K, Bakker A, Demerouti E, Shimada K, Kawakami N. Work-to-family conflict and family-to-work conflict among Japanese dual-earner couples with preschool children: A spillover-crossover perspective. J Occup Health. 2013;55(4):234-43, https://doi.org/10.1539/joh.12-0252-OA.

30. Shimazu A, Bakker AB, Demerouti E. How job demands affect an intimate partner: A test of the spillover-crossover model in Japan. J Occup Health. 2009;51(3):239-48, https:// doi.org/10.1539/joh.L8160.

31. Matthews RA, del Priore RE, Acitelli LK, Barnes-Farrell JL. Work-to-relationship conflict: Crossover effects in dualearner couples. J Occup Health Psychol. 2006;11(3):228-40, https://doi.org/10.1037/1076-8998.11.3.228.

32. Hammer LB, Bauer TN, Grandey AA. Work-family conflict and work-related withdrawal behaviors. J Bus Psychol. 2003; 17(3):419-36, https://doi.org/10.1023/A:1022820609967.

33. Spector PE, Jex SM. Development of four self-report measures of job stressors and strain: Interpersonal Conflict at Work Scale, Organizational Constraints Scale, Quantitative Workload Inventory, and Physical Symptoms Inventory. J Occup Health Psychol. 1998;3(4):356-67, https://doi. org/10.1037/1076-8998.3.4.356.

34. National Cancer Institute [Internet]. Bethesda: The Institute; 2017 [cited 2016 Aug 7]. Schwarzer R, Łuszczyńska A. Self-efficacy, 2008. Available from: https://cancercontrol. cancer.gov/brp/research/constructs/self_efficacy.html\#1.

35. Bandura A. Guide for constructing self-efficacy scales. In: Pajares F, Urdan T, editors. Self-efficacy beliefs of adolescents. Greenwich: Information Age Publishing; 2006. p. 307-37.

36. Cohen J, Cohen P. Applied multiple regression/correlation analysis for the behavioral sciences. Hillsdale: Erlbaum; 1983.

37. Konarski R. [Structural equation modeling. Theory and practice]. Warszawa: Wydawnictwo Naukowe PWN; 2010. Polish.

38. $\mathrm{Hu} \mathrm{L}$, Bentler PM. Cutoff criteria for fit indexes in covariance structure analysis: Conventional criteria versus new alternatives. Struct Equ Modeling. 1999;6(1):1-55, https:// doi.org/10.1080/10705519909540118.

39. Hayes AF. Introduction to mediation, moderation, and conditional process analysis: A regression-based approach. New York: Guilford Press; 2013.

40. Matthews RA, Wayne JH, Ford MT. A work-family conflict/subjective well-being process model: A test of competing theories of longitudinal effects. J Appl Psychol. 2014;99(6):1173-87, https://doi.org/10.1037/a0036674. 
41. Benight CC, Cieslak R., Molton IR, Johnson LE. Self-evaluative appraisals of coping capability and posttraumatic distress following motor vehicle accidents. J Consult Clin Psychol. 2008;76(4):677-85, https://doi.org/10.1037/0022-006X.76.4.677.

42. Kelly EL, Kossek EE, Hammer LB, Durham M, Bray J, Chermack K, et al. Getting there from here: Research on the effects of work-family initiatives on work-family conflict and business outcomes. Acad Manag Ann. 2008;2: 305-49, https://doi.org/10.1080/19416520802211610.
43. Eaton SC. If you can use them: Flexibility policies, organizational commitment, and perceived performance. Ind Relat. 2003;42(2):145-67, https://doi.org/10.1111/1468-23 2X.00285.

44. Sweet S, Pitt-Catsouphes M, Besen E, Golden L. Explaining organizational variation in flexible work arrangements: Why the pattern and scale of availability matter. Community Work Fam. 2014;17(2):115-41, https://doi.org/10.1080/13668 803.2014.887553.

This work is available in Open Access model and licensed under a Creative Commons Attribution-NonCommercial 3.0 Poland License - http://creativecommons.org/ licenses/by-nc/3.0/pl/deed.en. 